Results Median age at diagnosis was 51 years old, median tumor size was $28 \mathrm{~cm}$. Node positive disease was observed in $68.5 \%$ of cases, grade III in 26.8\%, median ki67 was 27. Overall, the PREDICT tool underpredicted 5-year OS by $6.6 \% \quad(80.8 \%, \quad 95 \% \mathrm{CI}[70.8 \%-90.84 \%] \quad$ vs $\quad 87.4 \%$, 95\%CI [86.4\%\%-92.4\%]). This underestimated difference was observed among several subgoups: in $\mathrm{pN} 1-3$ group it was 6.4\% (78.6\% [68.1\%-89.1\%] vs $85 \%[81.1 \%-89.8])$, in menopausal women it was $-7.9(77.4 \%[67.3 \%-87.4 \%]$ vs $85.3 \%$ [75.3-95.3]) and it patients who received chemotherapy it was $-8.6 \%$ (80.9\% [71.3\%-90.5\%] vs 89.5 [86.4\%-92.6]). On the other hand, the PREDICT overestimated survival in younger patients $\leq 40$ years old by $+6.1 \% \quad(78.5 \%$, 95\%CI [68.5\%$88.5 \%$ ] vs $84.6 \%$ 95\%CI [75.9\%-93.2\%]). The ROC analysis of PREDICT showed a medium discrimination value with an AUC of 0.61 (95\% CI: 0.51-0.73).

Conclusions PREDICT UK 2.1 showed an under estimation of the 5 -year survival of $-6.6 \%$, conversely it overestimated it in younger patients by $+6.1 \%$. These results highlight the challenge of survival evaluation in $\mathrm{RH}+\mathrm{HER} 2$ - intermediate risk breast cancer.

\section{EPV022/\#433 BREAST CANCER SCREENING AND THE DYNAMICS OF AGE-RELATED INCIDENCE AND EARLY BREAST CANCER IN KAZAKHSTAN}

${ }^{1} \mathrm{D}$ Kaidarova*, ${ }^{2} \mathrm{~A}$ Zhylkaidarova, ${ }^{3} \mathrm{M}$ Saktaganov. ${ }^{1}$ Kazakh Institute of Oncology and Radiology, Head of Kazior, Almaty, Kazakhstan; ${ }^{2}$ Kazakh Institute of Oncology and Radiology, Department of Monitoring and Evaluation of Cancer Care and Screening, Almaty, Kazakhstan; ${ }^{3}$ Kazakhstan School of Public Health, Public Health, Almaty, Kazakhstan

\subsection{6/ijgc-2021-IGCS.89}

Objectives Purpose of the research is to assess some screening indicators and its impact to the epidemiological picture of $\mathrm{BC}$ in Kazakhstan.

Methods This study is retrospective. Traditional methods of statistical processing of the material were used. 60,480 BC cases were registered in 2004-2019. In BC screening $4,149,166$ women aged 50-60 years were examined in 20082017 and 1,624,667 women 40-70 years in 2018-2019. 9,340 BC cases were identified. To assess the impact of screening, the epidemiological indicators were studied before screening (2004-2008, period A) and after implementation (2009-2019, period B).

Results The BC incidence since period A increased from 37.6 per 100000 in $2004-2008$ to 51.6 in 2019 . In period A the largest number of $\mathrm{BC}$ cases was recorded at the age of 45-54 years, the second peak was noted at the age of 65-69 years. In period B the peak of cases was noted in group of 50-59 years. The increase of new cases in the 5054 age was $30 \%$, in the 55-59 age $62.5 \%$, in the 60-64 age - 118\%! After screening introduction a significant increase of $\mathrm{BC}$ was noted in age groups over 50 . Thus, the increase in the group of 50-54 year was 11\%, in the group of $55-59-20.3 \%$, in the group of $60-64$ year $-28.2 \%$, in the 65-69-35.9\%. There is an increase of localized forms (stages I-II) from $69.8 \%$ to $86.9 \%$, a decrease of advanced $\mathrm{BC}$ in period $\mathrm{B}$.

Conclusions The results of the study showed the effectiveness of BC screening in Kazakhstan.

\section{EPV023/\#441 PATHOLOGIC FINDINGS IN PREMENOPAUSAL PATIENTS WITH RECEPTOR-POSITIVE METASTATIC BREAST CANCER UNDERGOING BILATERAL SALPINGO-OOPHORECTOMY}

${ }^{1} \mathrm{M}$ Wagner*, ${ }^{1} \mathrm{C}$ Anton, ${ }^{1} \mathrm{~J}$ Carvalho, ${ }^{2} \mathrm{~L}$ Testa, ${ }^{1} \mathrm{~A}$ Ennes, ${ }^{1} \mathrm{E}$ Mayerhoff. ${ }^{1}$ Instituto do Câncer do Estado de São Paulo, Ginecologia E Obstetrícia, Sao Paulo, Brazil; ${ }^{2}$ Instituto do Câncer do Estado de São Paulo, Oncologia Clínica, Sao Paulo, Brazil

\subsection{6/ijgc-2021-IGCS.90}

Objectives To evaluate pathologic findings and access risk factors in premenopausal patients with hormone receptor-positive metastatic breast cancer undergoing bilateral salpingo-oophorectomy (BSO) for hormone supression.

Methods We retrospectively analyzed data of 170 premenopausal patients with hormone receptor-positive metastatic breast cancer who had been submitted to BSO for ovarian supression between 2009 and 2021 at a terciary hospital in São Paulo, Brazil. All patients were metastatic at the time of surgery, but none had known ovarian metastasis. Patients with preoperative suspicion for malignancy in ovaries were not included. The following characteristics were analyzed: age, BMI, histological type, molecular subtype, HER2 status, initial TNM staging, sites of distant metastases at surgery, number of sites of distant metastases at surgery and the family history of cancer.

Results A total of 170 patients were included. The characteristics of the studied patients are described in table 1. Unknown

Abstract EPV023/\#441 Table 1 Characteristics of the population

\begin{tabular}{|c|c|c|c|}
\hline \multirow[b]{2}{*}{ Characteristic } & \multirow{2}{*}{$\begin{array}{c}N \\
(N=170)\end{array}$} & \multicolumn{2}{|c|}{ Anatomopathological Results of Ovaries } \\
\hline & & $\begin{array}{l}\text { Metastatic Breast Cancer } \\
N=40 \text { (24\%) }\end{array}$ & $\begin{array}{l}\text { Neoplasia Absent } \\
\text { N=130 (766) }\end{array}$ \\
\hline Age, median & $41(26.59)$ & $40(26.59)$ & $42(26-55)$ \\
\hline $\begin{array}{l}\text { Body Mass Index, median } \\
\text { Histological Type }\end{array}$ & $27(15,6-41,4)$ & $24.7(17.3-36.6)$ & $26.7(15.6-41.4)$ \\
\hline Invasive Ductal Cartinoma & 160 & $32(20 \%)$ & $128(80 \%)$ \\
\hline Invasive Lobular Carcinoma & 10 & $8(8006)$ & $2(20 \%)$ \\
\hline \multicolumn{4}{|l|}{ Molecular Subtype } \\
\hline Luminal A & 18 & $7(39 \%)$ & $11(61 \%)$ \\
\hline Luminal B HER2 negative & 114 & $25(22 \%)$ & $89(78 \%)$ \\
\hline Luminal B HER2 positive & 15 & $1(7 \%)$ & $14(93 \%)$ \\
\hline Unknown & 23 & $7(30 x)$ & $16(70 \%)$ \\
\hline \multicolumn{4}{|l|}{ HER2 Status } \\
\hline Negative & 145 & $38(26 \%)$ & $107(74 \%)$ \\
\hline Positive & 24 & $2(8 \%)$ & $22(92 \%)$ \\
\hline Unknown & 1 & 0 & $1(100 \%)$ \\
\hline \multirow{2}{*}{\multicolumn{4}{|c|}{$\begin{array}{l}\text { Initial Staging } \\
\text { Tumor Stage }\end{array}$}} \\
\hline & & & \\
\hline $\mathrm{T} 1$ & 13 & 0 & $13(100 \%)$ \\
\hline 12 & 43 & $11(26 \%)$ & $32(74 \%)$ \\
\hline 13 & 61 & $16(26 \%)$ & $45(74 \%)$ \\
\hline T4 & 45 & $12(27 \%)$ & $33(74 \%)$ \\
\hline Unknown & 8 & $1(12.5 \times)$ & $7(87.5 \%)$ \\
\hline \multicolumn{4}{|l|}{ Nodal Status } \\
\hline No & 20 & $4(20 \%)$ & $16(80 \%)$ \\
\hline N1 & 71 & $16(22.5 \%)$ & $55(77.5 \%)$ \\
\hline N2 & 49 & $10(20 \%)$ & $39(80 \%)$ \\
\hline N3 & 21 & $9(43 \%)$ & $12(57 \%)$ \\
\hline Unknown & 9 & $1(11 \mathrm{x})$ & $8(89 \%)$ \\
\hline \multicolumn{4}{|l|}{ Distant Metastasis } \\
\hline Mo & 62 & $17(27 \% 6)$ & $45(73 \%)$ \\
\hline M1 & 107 & $23(21.5 \%)$ & $84(78.5 \%)$ \\
\hline \multirow{2}{*}{\multicolumn{4}{|c|}{ Locals of Distant Metastasis }} \\
\hline & & & \\
\hline \multicolumn{4}{|l|}{ at Surgery } \\
\hline Bone & 118 & $29(25 \%)$ & $89(75 \%)$ \\
\hline Liver & 39 & $10(26 \%)$ & $29(74 \%)$ \\
\hline Lung & 35 & $9(26 x)$ & $26(74 \%)$ \\
\hline Lymph nodes & 31 & $7(23 \%)$ & $24(78 \%)$ \\
\hline Pleura & 17 & $9(536)$ & $8(47 \times)$ \\
\hline cNS & 9 & $6(67 x)$ & $3(33 \times)$ \\
\hline Skin & 4 & $2(50 \% 6)$ & $2(50 \%)$ \\
\hline Peritoneum & 3 & $2(67 \%)$ & $1(33 \times)$ \\
\hline & 10 & $3(30 \%)$ & $7(70 \%)$ \\
\hline \multicolumn{4}{|l|}{ Number of Sites of Distant } \\
\hline \multicolumn{4}{|l|}{ Metastasis at Surgery } \\
\hline 1 & 89 & $15(17 \%)$ & $74(83 \%)$ \\
\hline 2 & 51 & $15(29 \%)$ & $36(71 \%)$ \\
\hline 23 & 22 & $9(41 x)$ & $13(59 \%)$ \\
\hline Unknown & 8 & $1(12.5 \%)$ & $7(87.5 \%)$ \\
\hline \multicolumn{4}{|l|}{ Family History of Cancer } \\
\hline No history & 102 & $26(25 \%)$ & $76(75 \%)$ \\
\hline Breast cancer & 49 & $10(20 \% 6)$ & $39(80 \%)$ \\
\hline Colorectal cancer & 18 & $5(28 \times 6)$ & $13(72 \%)$ \\
\hline Prostate cancer & 9 & $3(336)$ & $6(67 \%)$ \\
\hline Pancreatic cancer & 3 & $1(33 \%)$ & $2(67 x)$ \\
\hline Ovarian cancer & 2 & 0 & $2(100 \%)$ \\
\hline
\end{tabular}

